\title{
STUDY REGARDING SOCIALIZATION AND SOCIAL INTEGRATION OF STUDENTS
}

\author{
Marcel POMOHACI* \\ marcelpomohaci@yahoo.com \\ Ioan Sabin SOPA** \\ sopa_sabin@yahoo.com \\ * "LUCIAN BLAGA" UNIVERSITY, SIBIU, ROMANIA \\ **NATIONAL UNIVERSITY OF PHYSICAL EDUCATION AND SPORT, BUCHAREST, ROMANIA
}

\begin{abstract}
Motor activities, whether organized sports and physical education, sports training, leisure activities or competition, have at this age level, primary education, a strong playful time, pursuing both development and motor skills, physical fitness and especially the psycho-social. Through play and sports competition, the child can gain confidence and try new forms of communications so that he can express his potential and qualities.

Theory of social learning has shown that socialization is made best in the sports. According to specialists, practicing physical activities or sports influences youth personality and creates positive effects on body and mind.

Using sociological questionnaire method we tried to analyze the importance of motor activities in the process of socialization and social integration of students, the relationships established within the group and the influence of sport in group evolution.
\end{abstract}

\section{KEYWORDS:}

Adaptation and social integration, motor activities, socialization, group dynamics

\section{Introduction}

Motor activities are the perfect framework in developing young generations, being a social factor with increasing importance in contemporaneous society (Sopa \& Pomohaci, 2014). 
The phase of transition from preschool to school is a test for the small scholar, his whole social environment, rules and rigors are changing, and it can disrupt his behavior thereby occurring problems of adaptation and integration in the social group. Motor activities, at this age level, are learned mostly through playing, which gives to the young scholar the perfect framework for socializing, relaxing him and taking off his anxiety.

Mărgineanu G.N. (2013) states "although he takes part from the same group class, in physical education and sports class, the student no longer retains the usual place in the classroom, no longer relate mainly to his bank colleague, but stands in the lineup in height order, bordering colleagues, practice in pairs and groups, becoming a member of teams that are competing and whose composition changes from one lesson to another, is encouraged by fellow team members, encourage their teammates, enjoy in collective the victory, feels the sadness of failure among his colleagues, etc. All these aspects, extend child relationship system, it gets used to the framework and activate in different groups, attenuates individualist spirit. Exercising rotating roles (in charge of the group, team captain, supervisor of compliance with the rules set), gets the student used to leadership and subordinate relationships, binding in compliance with the rules established by proper manifestation in any circumstance.

Socialization process helps shape the mental traits and personality; those traits are formatted as a continuous process as summing and exercising new social roles and acquiring new experiences. This period of forming and primary socialization is fundamental to the future development of the child" (Mărgineanu, 2013).

Defining socialization through sport Epuran M., (1998) states: "Socialization through sport means the extent to which attitudes, values, skills, characteristics learned in sport are transferred and manifested in other social activities and institutions.
Constantinescu A., (2009) summarizes the importance of communication in the socialization process through motor activities saying "socialization is a progressive and an accumulating process in which children, over the period of growth, assimilates the behaviors, values, codes, roles, habits conventions and ways of thinking characteristic of the socio-cultural environment. Good socialization is achieved using communication". Also here the author underscores the idea that "the process of socialization facilitates, at the same time, the normal existence of social life, providing stability and proper functioning of social structures, cohesion and intergroup socialization". Individuals assimilate a whole system of knowledge, attitudes, skills and moral rules required to enter the social life community, developing imagination and creative capacity at the same time with the affection necessary to moral and psychological balance.

School group cohesion is very important in the evolution of performance as a group, so from the observation that in groups where there are positive relations of sympathy, friendship, and cooperation the work is most effective, in this study, we have tried to analyze and develop a scholar group cohesion at primary level (Sopa, 2013).

Socialization through sport can improve team cohesion; better communication can help in the process of integration of members (Sopa \& Szabo, 2015).

Group cohesion was analyzed by many researchers, most of them describing this group cohesion as the strength of bonds between group members, the unity of a group, the feeling of attraction between group members, the degree to which members concentrate their efforts to achieve group goals (Sopa \& Pomohaci, 2015 a).

The integration into a high cohesive group offers possibilities for a more in-depth exploration (Sopa \& Pomohaci, 2016 a).

Successful teams are built around strong leaders and the importance of this role is growing in the nowadays sport in all 
categories. The presence of leaders is mostly seen in interactive games and during matches, their performance influences other colleagues on the team. The effectiveness of leaders upon team performance is less important in co-active settings, but not entirely absent (Sopa \& Pomohaci, 2016 b).

\section{Objectives}

The objectives of this study seek to demonstrate the importance of motor activities in personality development of scholar, socialization, communication and integration into social groups, sports and being an ideal framework facilitating the achievement of these objectives.

\section{Materials and Methods}

The research methods used were: bibliographic study, observation method, questionnaire method for groups.

4. The Research Hypothesis

Primary period is the stage of forming and cognitive and moral development of individuals, thereby if students will participate in activities that have a strong socializing character, then they will learn moral values like honesty, modesty, courage, and not least teamwork. If we will give attention to motor activities at the primary level to social activities then we will have children that will be sociable, will integrate smoothly into an unknown environment without panic, they will behave freely, will connect faster and make friends and will know the limits to be imposed in certain relationships.

\section{Research Sample}

The research sample was formed by class II A with an effective of 20 students (11 girls, 9 boys), control class and experimental class II B with an effective of 20 students (10 girls, 10 boys). In researching these two school groups we had as the main objective to analyze and demonstrate the socializing role of motor activities at primary level.

\section{The Research Content}

In this research, we used the questionnaire and the observation method. The observation method is one of the methods most commonly used for psychosocial research, applied and organized relatively easily, can be quickly adapted and used in various situations in analyzing the evolution of groups and can be used in varied forms depending not only on the objective of the investigation, as well as the nature of the group. With this method, we can follow and record behavioral manifestations in various social situations individually or psychosocial interaction, as the psychological analysis of the whole group or a particular individual.

One of the objectives of the research was to analyze inter-group social relations, so we were concerned about capturing some aspects and phenomena that characterize social groups and the mark of motor activities of students in different stages of socialization activity: physical education class, sports, extracurricular activities, sports training, competition activities soon.

Observation combined with various discussions with these groups of students helped us getting information on existing relations in the class, affective communication between students, group decision making, resolving various disputes regarding the group, the degree of socialization, communication and integration of group members.

The main objective of the research was to discover the different aspects of socialization and the degree of social integration of students through motor activities.

The first sample group (the experimental) was involved in a sports project initiation and selection which involved training students in basketball, so the young scholars had extra-curricular 2-3 trainings per week, also participated in numerous competitions and during physical education classes we focused on team games, relay races, competitions in which students have been required to exercise the capacity of cooperation, communication and socialization. The second sample of students (the control sample) had normal 
physical education classes focused on individual sports such as gymnastics, athletics, chess, badminton where the process of socialization, communication and relationship is not strongly developed.

Besides the observation method, we used the research method of group questionnaire, so we developed a 15 item questionnaire that examines issues within the group socialization, communication, member relationships, and member's acceptance ability.

7. Results

Following the responses of our students, we had achieved the following graphs:

Graphic no. 1 Practicing sport with pleasure with every occasion

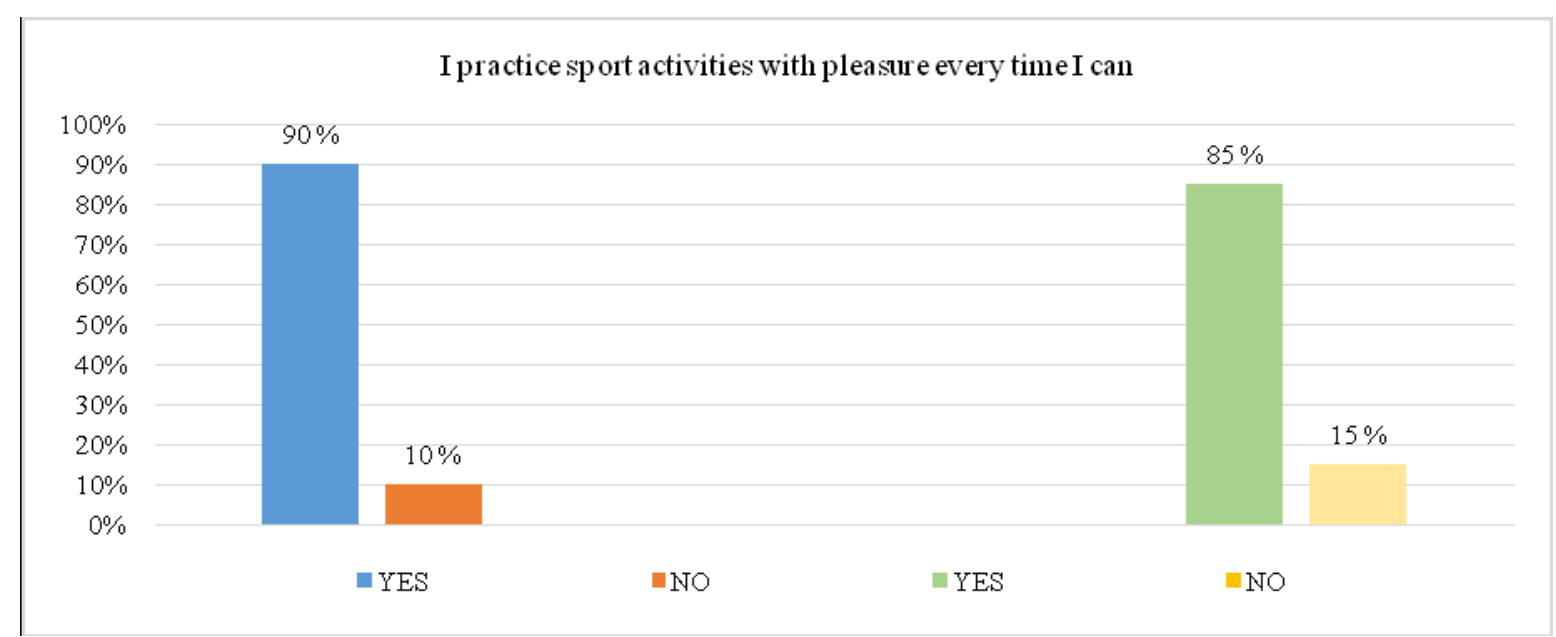

Analyzing student responses we can see that the desire and availability for physical activity is very high, whether it is physical education classes and sports competitions or training sessions, children from both samples have a high desire and about the same participation desire for such activities.

Graphic no. 2 Working with team in sport activities

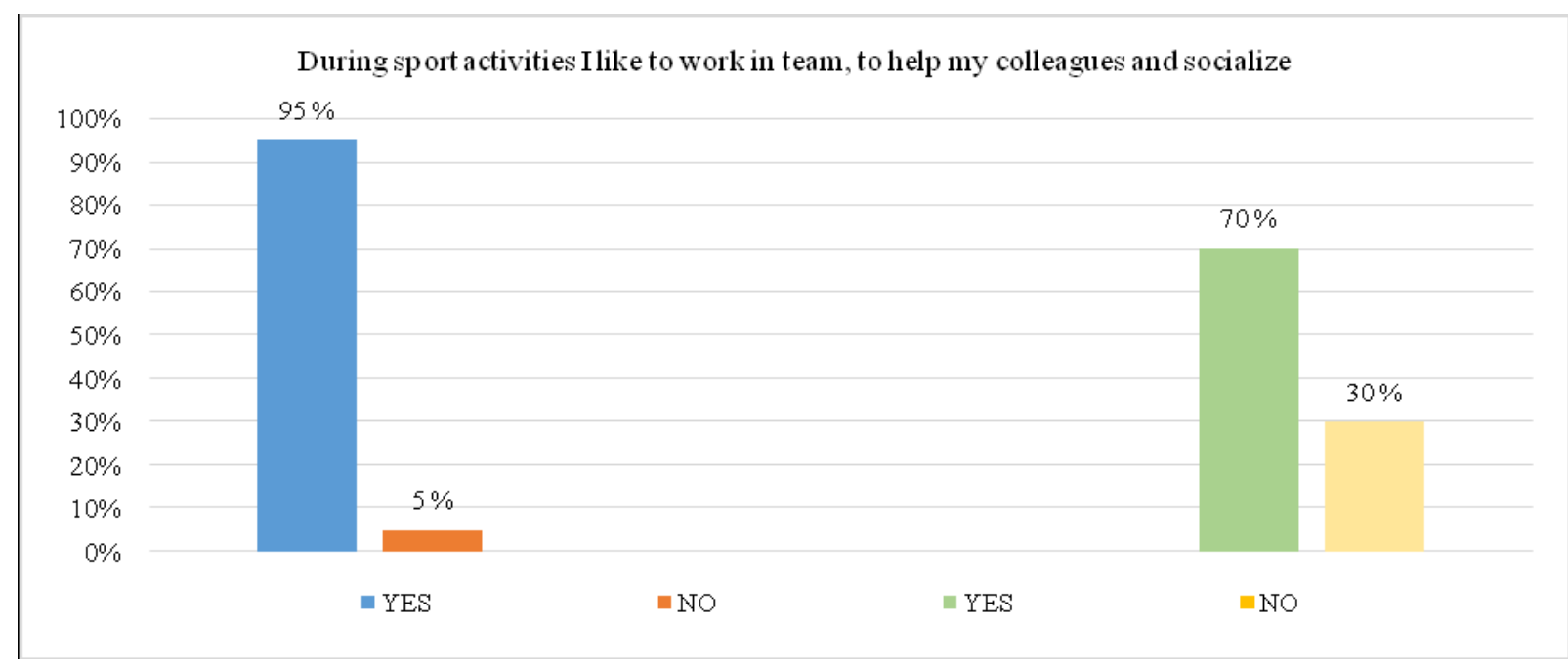


Looking at the chart above, the students belonging to the experimental sample recorded 19 positive responses, with an affirmative response rate of $95 \%$, and only one negative response that represents $5 \%$, and the control sample recorded 14 positive responses, $70 \%$ of total, and
6 negative responses that represent $30 \%$ of total, so we can conclude that students in the experimental group who practice team sports, relay races, competitions between teams, like to work in a team and likes to team up, communicate and socialize easier.

Graphic no. 3 Socializing with friends in sport activities

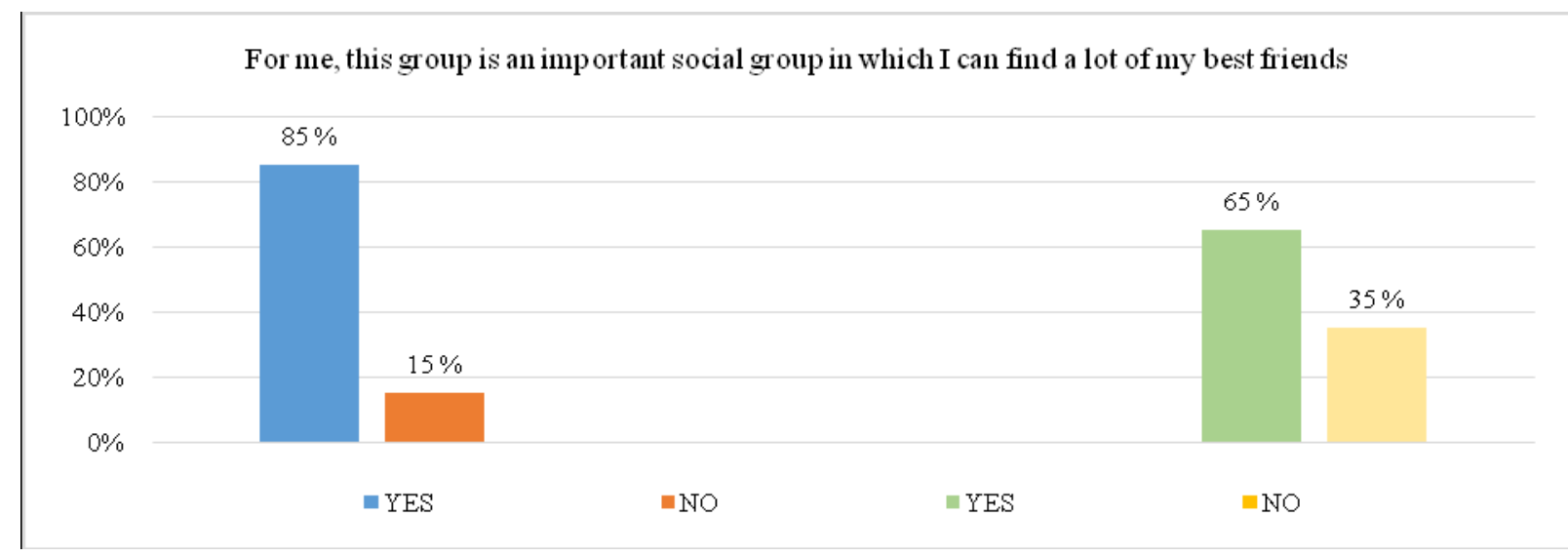

Regarding the item "For me, this class is an important social group which includes many friends of mine", 17 students from the experimental sample representing $85 \%$ said yes, while the control group were recorded answers, percentage of only $65 \%$, indicating that the groups that practiced team sports, children succeed to communicate and socialize effectively making lasting friendships, while in the control group which practice individual sport and with a reduced frequency prefer to find friends in other activities other than sports.

Graphic no. 4 Practicing sport in team or individual

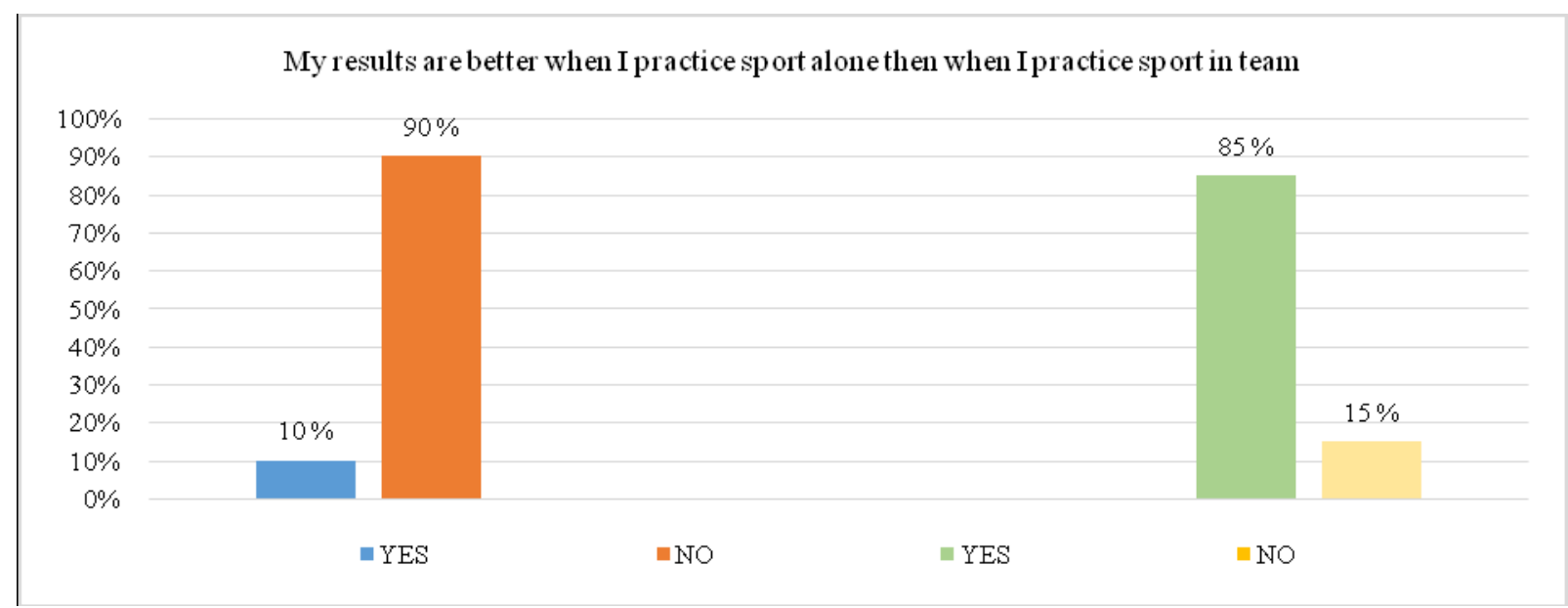


At the question "My results are better when I do sports alone than when I practice sport in a team", 18 students in the experimental sample, representing $90 \%$ of the respondents, answered negative, two of them, representing $10 \%$, responded positively. Regarding the control group situation is opposite, 17 students, representing $85 \%$, responded positively and only three students, representing $15 \%$ of the total, responded negatively, which indicates that the experimental group obtained higher performance and satisfaction through teamwork, as opposed to the control group who loves to play and perform alone.

Graphic no. 5 Missing your colleagues when school ends

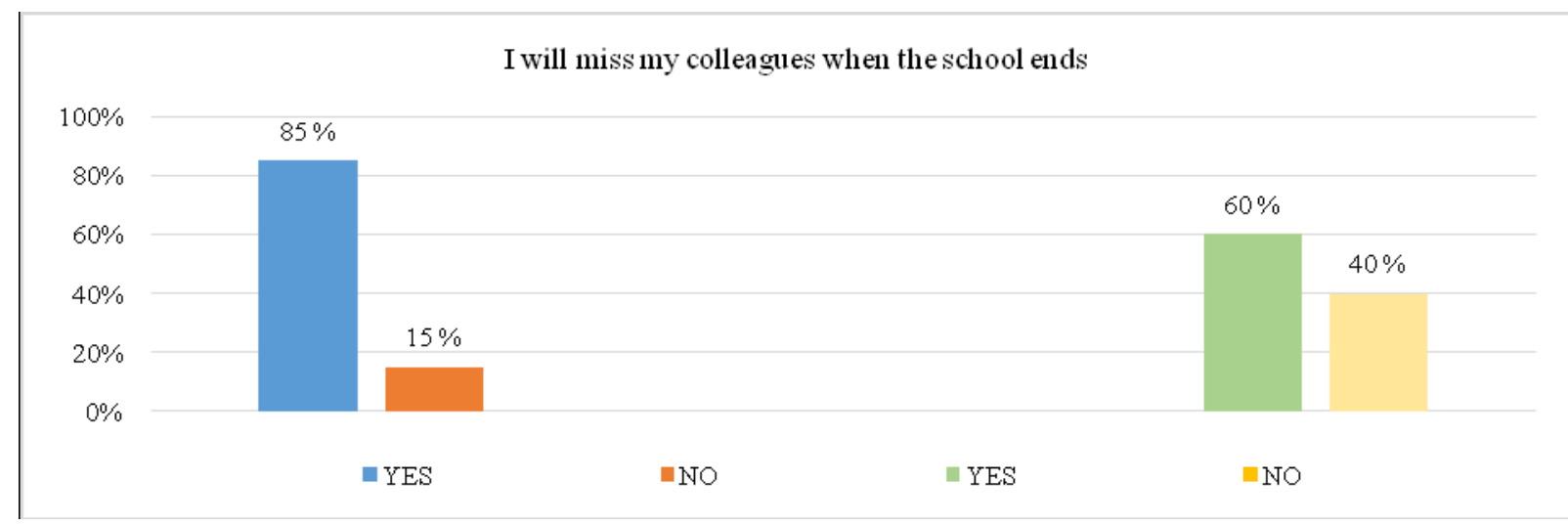

When asked if "I will miss my colleagues when the school year ends", 17 students, representing $85 \%$ of total, answered positively and only 3 of them, representing $15 \%$ of the total, answered negative, in the situation in the sample group the answers were 12 negative responses, representing $60 \%$ and 8 positive responses, representing $40 \%$. Analyzing the results obtained in this item we can conclude that the experimental group teamwork has made its mark on group cohesion, socialization and communication developing lasting friendships and relationships. In the control group bonds between group members are not as welded and not immediate needs, students establishing just relations of friendship not exceeding the state of pals.

Graphic no. 6 Spending time socializing before and after the class ends

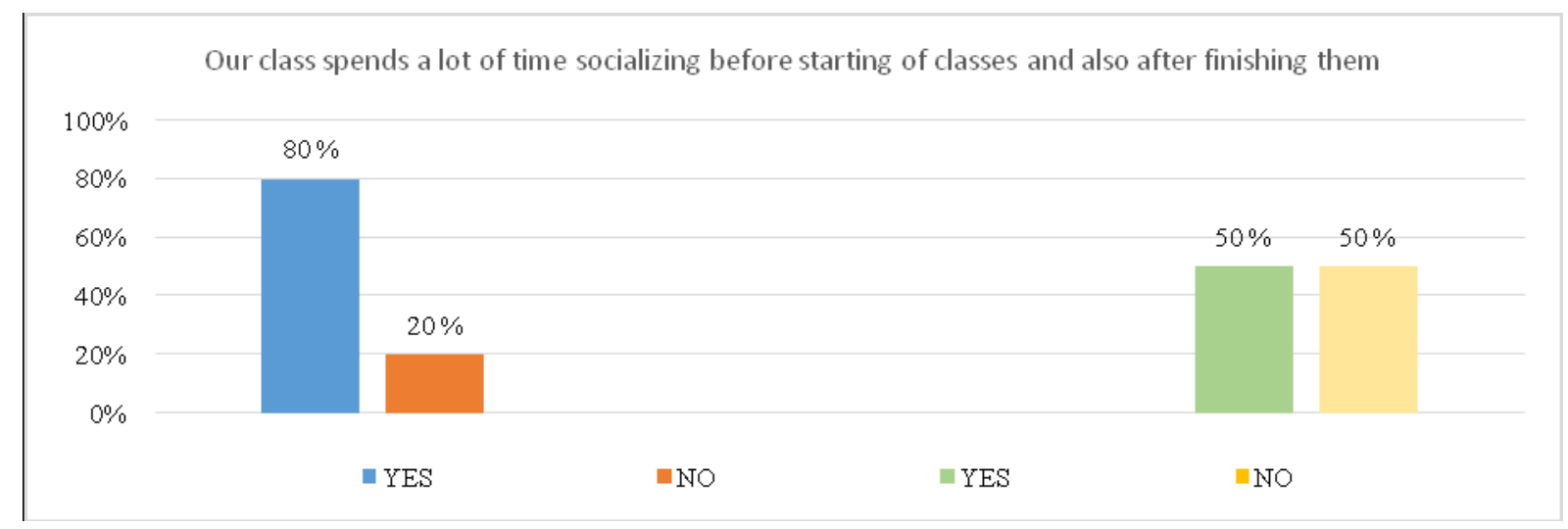

At the question "Our class spends a lot of time socializing before starting classes and also after finishing them" 16 students from experimental group said yes, representing $80 \%$ of the total, and only
4 gave negative response, accounting for $20 \%$ of all students, and in the control group positive responses were equal to the number of negative responses 10 , accounting $50 \%-50 \%$, which reinforces 
our belief that the experimental group practicing team sports communicate, socialize and have interest to organize itself even before and after the end of sport activities, while the control group only one side is interested in communicating with colleagues outside working hours.

Graphic no. 7 Helping each other

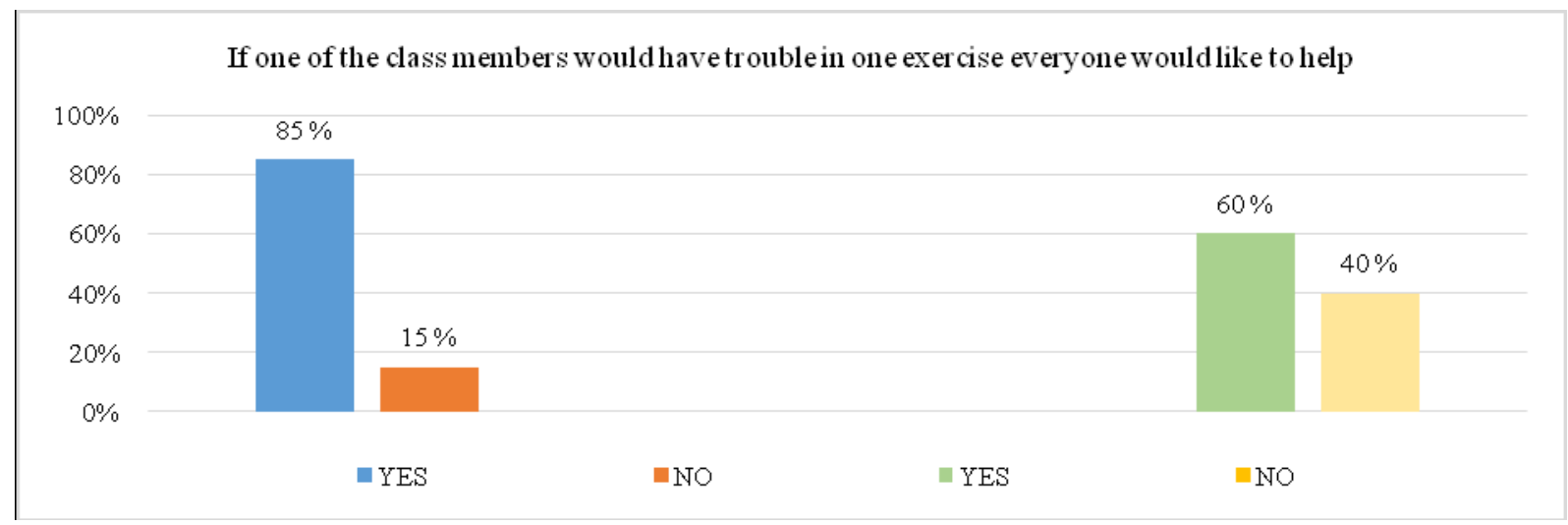

At the statement "if one of the class members would have trouble in one exercise everyone would like to help", experimental sample answered: 17 students yes, representing $85 \%$ of total, 3 students answered negative, representing $15 \%$ of pupils, and the control group, 12 students answered yes, summing $60 \%$ from the total and 8 students responded negatively, representing $40 \%$ from the total, so we can conclude that in case of a problem the group with better cohesion, effective communication and socialization answer better, these communication and socialization processes develop social skills, spirit of self-help, cooperation, team spirit, spiritedness, while in the control group some members would prefer not to interfere in colleagues matters and let them fend for themselves.

\section{Conclusions}

The conclusions of this study highlight the results of the experimental sample in which we acted to develop socialization, communication, group cohesion through sports, team sports, contests, relay races, competitive activity, students developing team spirit, mutual aid, cooperation, social integration.

So we can say that "sport and physical activity contribute to the socialization of men and especially young people. Sports and physical education, promote respect for moral values in both the Olympic spirit and the core values of life in the community, favoring the integration of the group and communication skills" (Sopa \& Pomohaci, 2016 b).

Cârstea G. (1981) said about socializing character of sport "relationships created in by participants in various competitions circles are unusually durable and exercise an important role in social microstructure formation" or "sport is a good opportunity of self-revealing in open contact with others, it approaches the participants in these games, generates links between persons, attitudes and modes of behavior" Also for analyzing socialization, group cohesion and social integration we can use sociometric test for understanding the psycho-social integration in group (Sopa \& Pomohaci, 2015 b).

Sociometry is a way of measuring relationships between people. These sociometric tests can discover, describe and evaluate social status and structure, and can measure the acceptance or rejection felt between sport groups. Subjects within a sport group are usually asked to pick members that they like or prefer working with, or choose their lieder, or other variables depending on the context (Sopa, Sanislav \& Pomohaci, 2013). 


\section{REFERENCES}

Cârstea, G. (1981). Sociology of Sport. Bucharest: Physical Education and Sports Institute, p. 21.

Constantinescu, A. (2009). Characteristics of the human communication in the socializing process through sport. International Conference: Innovation and Creation in the Field of Physical Activity, Galaţi, May 29-30, p. 56.

Epuran, M. (1998). Aspects of socialization in sports. Physical and sporting activities social and performance”, National Scientific Conference CSSR), p. 5.

Mărginean, G.N. (2013). Physical education and sport at primary. Sibiu: "Lucian Blaga" University, p. 23.

Sopa, I.S. (2013)._Study regarding group cohesion at primary school level. International Scientific Conference Youth in the perspective of the Olympic Movement, Brassov, Romania, Published in Buletin of the Transilvania University of Braşov, Vol. 7 (56) No. 1, 2014, Series IX-Sciences of Human Kinetics.

Sopa, I.S. \& Pomohaci, M. (2014). Study regarding the importance of motor activities in the process of socialization and social integration of students. International Scientific Conference "Perspectives in Physical Education and Sport", Constanţa, $14^{\text {th }}$ Edition, $23^{\text {th }}-24^{\text {th }}$ May.

Sopa, I.S., Sanislav, M. \& Pomohaci, M. (2014). The Importance and Utility of the Sociometric Survey Method in Physical Education Research. Procedia - Social and Behavioral Sciences, Elsevier Publication, Volume 117, pp. 185-192.

Sopa, I.S. \& Szabo, D.A. (2015). Study Regarding the Importance of Developing Group Cohesion in a Volleyball Team. Procedia Social and Behavioral Sciences, Elsevier Publication, Volume 180 C, pp. 1343-1350.

Sopa, I.S. \& Pomohaci M. (2015 a). Developing Cohesion in Sportive Group through the Socializing Means of Motor Activities. Bologna: Medimond Publishing Company by Editografica, p. 135.

Sopa, I.S. \& Pomohaci, M. (2015 b). Methodical discipline of Volleyball. Lambert Academic Publishing, ISBN-13: 978-3-659-78757-7.

Sopa, I.S. \& Pomohaci, M. (2016 a). Tehnics of communication and social integration through sport, Lambert Academic Publishing, ISBN-13: 978-3-659-86350-9.

Sopa, I.S. \& Pomohaci, M. (2016 b). Finding the leader of a volleyball team using the socio metric survey method. The European Proceedings of Social \& Behavioral Sciences EpSBS, Volume IX, Editor: Future Academy.

Turcu, D.M. \& Todor, R. (2010). Socialization through sport. Effects of physical education and sport. The Annals of the "Stefan cel Mare" University V, No. 5, p. 128. 